\title{
The Impact of Public Health Expenditure on Health Component of Human Capital
}

\author{
Rasa Railaite, Ruta Ciutiene
}

Kaunas University of Technology

K. Donelaicio st. 73, LT-44029, Kaunas, Lithuania

E-mail.rasa.railaite@ktu.edu; ruta.ciutiene@ktu.lt

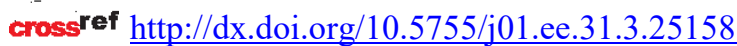

The analysis of the concept of human capital shows that this form of capital includes a set of different components that are used in economic activities and generates different kind of benefits. Health is one of the main components of human capital. Hence, considering its importance authors of this article tried to investigate the impact of public health expenditure on the health component of human capital. Ordinary least square, fixed and random effects panel data models for 28 European Union countries were used to reach this purpose. The main variables used in this study is life expectancy at birth (related to the health component of human capital) and general government health expenditure. It is known that there are other factors affecting health and human capital in general. Hence variables such as GDP grow, GINI coefficient, education level, alcohol consumption, old age dependency and urbanization rate were added in the models as explanatory variables. The results of the performed study show that public health expenditure has a positive and significant impact on the improvements of life expectancy. Selected fixed-effects panel data models also show significant and positive effects of the GDP growth, old age dependency while a negative effect is identified by alcohol consumption. The existing close relationship between health and education also is confirmed by this study. Results suggest that higher education level is positively and significantly related to life expectancy while a lower education has a negative impact on life expectancy.

Keywords: Public Health Expenditure; Health Input; Health Outcomes; Human Capital; Human Capital Factors.

\section{Introduction}

Scientific literature relates human capital to various types of micro and macro-economic benefits. Human capital is identified as a factor of an individual's income growth (Giziene, Simanaviciene \& Palekiene, 2012). Researchers such as Zhang \& Zhuang (2011), Fleisher, Li \& Zhao (2010) relate human capital to economic growth. However, it is also necessary to stress that health plays an important role in gaining this benefit of human capital. Human capital is a form of capital consisting of a set of different components that are embodied in individuals and used in their activities. Lim et al., (2018) define human capital as a level of population health and education. Furthermore, Poteliene \& Tamasauskiene (2014) define human capital by components such as education, knowledge, personal and innate features, skills, abilities, experience, emotional and mental health (p. 97).

Health is an important component in the concept of human capital and that is proved by several studies. First of all, Tchanturia, Beridze, Kurashvili (2015) identify capital of health as a factor affecting human capital formation. Bucinskas (2012) defines health as a form of human capital and also stresses that individuals' health state affects people's working capacities and the usage of human capital. Even though health is identified as a component of human capital, it is also closely linked with other components of human capital. Baldacci, Clements, Gupta, \& Cui (2008) relates better health with investment in education. Amadu, Eseokwea, \& Ngambi (2017) also highlight the importance of health in the concept of human capital. Direct links between health status and education are mentioned. According to Amadu et al. (2017) better children health is related to children education achievements and learning abilities, i.e. more time that can be spend at school. Investments in health are related to human capital stock improvements. Lim et al., (2018) stress that health investments have several kinds of impacts on human capital. First, health investments are related to improved health and also improved productivity, on the other hand, health investments are related to children health and their school attendance. Amadu et al. (2017), relates better health not only to human capital accumulation but also to such benefits as reduced absenteeism at work, increased worker productivity, higher savings or territorial attractiveness (p. 13). Bloom, Canning \& Sevilla (2004) note that, in the narrow sense, human capital is linked only to education, but in the broader sense, the health component is included. They emphasize the following advantages of a healthy workforce: increased energy, higher productivity and income, lower absenteeism from work due to poor health of themselves or their families. Bloom et al., (2004) attribute longer life expectancy to the number of employees with higher work experience.

Tchanturia et al., (2015) describe human capital development and highlight the importance of direction of state policy, population income growth, social and economic infrastructure, improvements in migration policy, civil society development and others. The importance of the public sector in investing in human capital can be justified by interpreting the impact through several channels. According to Marginean (2014) public funding seeks to increase access to health services, prevention and treatment when it is needed. Zakharova \& Kratt (2014) point out that public health care is carried out on the state budget. On the other hand, these researchers also highlight the importance of the country's 
legislation. Ferreira, Tavares, Quintal, \& Santana (2018) describe health system by highlighting its 3 main responsibilities: health improvement, treating and protection against the costs of illnesses.

Healthcare takes an important role in state policy and also in human capital formation. Human capital researchers such as Schultz (1972) identify health as a kind of investment in human capital. However, evidence of performed studies shows that there is no one common conclusion that higher public health expenditure leads to better health outcomes. The other issue is the efficiency of resource usage. Dang, Likhar, \& Alok (2016) stress that publicly funded health care systems have limited resources, so it is very important to choose effective health care interventions. On the other hand, Fujii (2018) also states that healthy people are a group that does not require high health care costs. The main goal of this study is to analyse the impact of public health expenditure to health component of human capital.

The present study consists of four major parts. In the first section authors review the existing literature investigating relationships between health expenditure and selected health outcomes or particularly country's human capital. The second part discusses the research methodology and the data of research. Empirical results are presented in the third part. Finally, the obtained results, and conclusions are summarised in the last part of the paper.

\section{Literature Analysis}

Even though health is one of the main components of human capital, and investments in health are identified as a type of investment in it, the discussion on whether higher health spending impacts on health outcomes remains. Further research is encouraged by the contradictions identified in the literature. The studies conducted differs in research methodology, country selected, and time period or dependent and independent variables analysed. However according to the results obtained performed studies can be divided into two groups: 1) studies that identify the positive and significant impact of public health expenditure; and 2) studies in which the effect is negligible, insignificant or negative.

A study carried by Filmer, Pritchett (1999) raise a question whether money matter and whether public health spending affects health outcomes. The results of performed cross-national data study shows that the effect of public spending is small but on the other hand changes in the health status is related to the country's income, inequality of its distribution, female education level ethnic fragmentation and predominant religion (p. 1309). Nixon, Ulmann (2006) performed an extensive literature analysis evaluating the relationships between health care expenditure and health outcomes. Empirically, this relationship was investigated by using data from European countries. Health expenditure contribution to improvements in life expectancy was identified as marginal. The results showed that during the evaluation period from 1980 to1995 health care expenditure added 2.6 years to males and 2.8 years to female life expectancy.

A case of health care performance in 18 Central and Eastern European countries was analysed by Anton \& Onofrei (2012). To express health outcome, the under 5 mortality rate was selected. The results indicated that the total health expenditure has significant influence (impact coefficient equal to - 0.64$)$ on the selected health outcome. It was also concluded that the GDP per capita, urbanization level and a number of physicians make an impact on health outcomes. Kim, Lane (2013) evaluated the impact of government health expenditure to health outcomes in 17 OECD countries during the period 1973-2000. The results of mixed effect panel data model estimation show that there is a positive relationship between public health spending and life expectancy. The identified public health expenditure coefficient is equal to 0.026 . Novignon, Olakojo, Nonvignon, (2012) also pointed out the expectation that investment in health (workforce and infrastructure) improve health and human capital. In their study the researchers (Novignon et al., 2012) analysed the effects of both public and private health expenditure on population health status in 44 sub-Saharan Africa region countries during the period of 1995-2010. The results show that public and private health care expenditure significantly affects health status and improve life expectancy. A comparison of private and public health expenditure shows that public health expenditure makes a higher impact. The public health expenditure effect coefficient was equal to 1.039 in the fixed effect model and 0.983 in the random effect panel data model. The coefficient of private health expenditure was equal to 0.528 and 0.443 . A negative and significant effect was identified by the HIV prevalence rate, while 3 variables expressing population age structure has insignificant effect to life expectancy. The effects of public and private health expenditure on health outcomes was also analysed by Homaie Rad et al., (2014). The analysis concludes that there are positive and significant relationships between public health expenditure and health status (expressed in infant mortality). The greater impact of private health spending on reducing infant mortality rates was found by Rahman, Khanam, (2018) who analysed the case of SAARC-ASEAN region countries. However, results of performed analysis did not identify a significant public or private health expenditure impact on life expectancy. When interpreting the results, the researchers considered other possible factors. In this case, the influence of education, environment, lifestyle was emphasized. The evidences of the performed study show that income growth and improved sanitation have a positive and significant effect on life expectancy.

Some empirical studies highlight the importance of government effectiveness in explaining the impact of public health spending. Farag et al., (2013) performed study of 133 low and middle income countries shows that the government health expenditure has significant impact in reducing infant and children under 5 years mortality. The results show that an elasticity of health spending on infant mortality are $0.13-0,33$ while on under 5 children mortality it is $0.15-0.38$. The researchers also draw attention to the importance of good governance, which is proven by the different effect coefficients. The impact of health spending on selected health outcomes is also assessed by Fujii (2018). This study evaluates not only the impact of public health expenditure but also private health spending. This researcher also emphasised the importance of government effectiveness. By compering private and public health spending Fujii (2018) identifies that on the average the greater impact is identified for private spending. However, results are different when the governments effectiveness is considered. Based on Fujii (2018), the impact 
of public health spending on health promotion is higher than private in the case of effective governments.

A case of 175 world countries over 16 years was analysed by Jaba, Balan, \& Robu (2014). These researchers also tried to estimate the relationship between health expenditure and life expectancy. In a comparison to the previously described studies, this analysis differs in the perspective taken. The case of analysed countries was grouped based on geographic position and income level. The results confirmed that there is significant relation between health expenditures and life expectancy. An existence of country effects also was identified. The highest health expenditure impact coefficient was identified in South-East Asia Region (0.045659), whereas, European countries have the lowest impact coefficient (0.001908). The results of the evaluation were also influenced by the country income level. The smallest effect of public health expenditure was identified in a high income group.

Performed literature review also has shown that the number of studies analysing the impact of public health spending on health outcomes is much expanded than the number of studies analysing the impact of these costs on human capital. Shuaibu \& Timothy (2016) after performed case of 33 African countries study made a conclusion that in the long run public health expenditure have a significant impact on human capital development (expressed in human development index (HDI)). A significant impact was also identified for public education expenditure, infrastructure and institutions. While the contemporaneous models presented different results where only institutional development was significant.

Prasetyo \& Zuhdi (2013) evaluated the efficiency of government health and education expenditure towards human development (expressed in HDI) in 81 countries. Based on the results of the analysis, the researchers identified a group of countries which are described as efficient in managing government health and education expenditure in a relation with HDI maximization. The list of the countries included "Armenia, Australia, Bangladesh, Chile, Georgia, Japan, Korea Republic, Lao PDR, Madagascar, Niger, Norway, Philippines, Sierra Leone, Singapore, US, and Zambia" (p. 620).

Part of studies analyse the impact of the government health spending on human capital and whether it makes an influence on country's economic growth. Oluwatobi \& Ogunrinola (2011) analysed a case of Nigeria. For a proxy of human capital the researchers used the total school enrolment and the total labour force while for human capital development variables such as government health and education expenditure were used. It was found thatthere is a long run relationship between human capital development and economic growth. The results indicate an existence of positive correlation between government recurrent expenditure and economic output. A positive bi-directional relationship between health expenditure and economic grow is also identified by Praise, GeorgeAnokwuru (2018). In this study education and health expenditure were used as proxies of human capital. Baldacci et al. (2008) analysed the relationships between social spending, human capital and economic growth in 118 developing countries. It is concluded that health expenditure has a positive impact on health capital expressed as an under 5 survival rate. However, this impact is defined as contemporaneous. Sapuan \& Sanusi (2013) performed an analysis of Malaysia. The gained results prove the importance of government expenditure in social services to human capital development and also country's economic growth.

In summary, part of studies discussed emphasize the importance of public sector in order to reach better results in the areas of health and human capital. On the other hand, Jaba et al. (2014) stress the importance of the relationship between resources and outcomes in the context of health system performance assessment. Explaining the impact of government expenditure Prasetyo, Zuhdi (2013) emphasize that this kind of expenditure make a contribution to reaching public goals. Novignon et al., 2012 also highlight that public sector participation is critical in order to improve health. They stress the importance of ensuring equitability and efficiency of goods and services such as health care infrastructure, health workforce, preventive health care provision.

The public sector takes an important role in healthcare. Fujii (2018) explains the possible impact of public health spending and notes that it could happen if created health care services improve a health status of society members. According to Filmer, Pritchett (1999) the impact of public spending is explained based on health production function and changes in health services consumption. They also stress the importance of a public sector efficiency and effective public health services. Explaining the impact of public health spending they also highlight the importance of the impact of net public sector. So Filmer, Pritchett (1999) emphasise 3 conditions that are needed for public spending impact creation. They stress that public health expenditure must create effective health services, these new services have to change the consumption of the total amount of health services. Lastly, the researchers highlight the importance of cost effectiveness of the public health services consumed. Considering contradictions in previous studies Kim \& Lane (2013) describe the possible theoretical reasons for them. It is argued that higher public health spending may not bring higher health outcomes due to public crowded out private sector provision, institutional inefficiencies and a lack of existing infrastructure necessary to access health care (p. 8). Rajkumar, Swaroop (2008) also point out the importance of governance quality and provide its justification based on the differences in public spending impact to child mortality of the education attainment.

The impact of public health spending is also related with changes in private health expenditure. According to Rahman, Khanam (2018) increased public health spending can reduce the burden of private spending and the personal spending ability to use goods and services. Increased public health spending is related with health and human capital improvements.

\section{Model Specification and Data}

\section{Dependent Variable}

In order to evaluate the impact of public health investment on human capital a proxy of human capital must be selected first. According to Lee, Ihm, \& Ryu, (2017) human capital is a non-tradable asset and the return of it is not measured directly. Literature analysis shows that human capital measurement is problematic and different researchers use different proxies to express human capital. In economic growth studies human capital is expressed by quantitative 
variables such as primary, secondary school, and higher education enrolment rate (Wolff, 2000), a ratio of employees with tertiary education on total number of employees, (Čadil, Petkovova, \& Blatna, 2014), share of labour force with secondary / tertiary education (Odoardi, Muratore, 2019), population (25-64 years) participating in education and training (Odoardi, Muratore, 2019), life expectancy at birth (Akpolat, 2014; Kokotovic, 2016), expenditure on education (Akpolat, 2014; Kokotovic, 2016) and others. For this study the life expectancy variable is selected as a dependent variable. From one side this variable is related with health state, on the other hand researchers also use this variable as a proxy of human capital.

\section{Independent Variables}

An analysis of scientific literature shows that health can be described as an input and output system (for example Anton \&Onofrei (2012); Nixon \& Ulmann (2006), Suhrcke et al., (2005). According to Suhrcke et al. (2005) health is affected by various inputs such as healthcare, genetics, lifestyle, education, wealth, environment and other socioeconomic factors. Jaba et al. (2014) also stress that the variation of life expectancy is explained by such factors that have direct effect like health expenditure, access to healthcare, persons education, income or lifestyle (p.112). Similarly, the whole human capital including health, education and other components is also affected by different groups of factors. According to Tchanturia et al. (2015) human capital formation and it's quality is related to internal and external factors. Opportunities to receive health care are separated as an external factors affecting human capital development. Public health expenditure is selected as the main input to the selected outcome, and additional control variables are also included in the study. The selection of the control variables is based on the practise of the previous empirical studies and theoretical justification. The selection of main input and other external environmental factors is based on the availability of annual statistical data. The variables included in the evaluation model are as follow:

Income (expressed as GDP per capita). The impact of the income on health is explained based on indirect channels. Income is related to better nutrition, housing and sanitation. A higher income level is also related to better consumption of public health and sanitation facilities or better education and its help to avoid preventable diseases (Fujii, 2018). The impact of income on health is also highlighted by Farag et al. (2013). They stress that income influence health through channels such as better nutrition, improved housing and sanitation and access to safer drinking water. Rahman, Khanam (2018) associate higher income with spending capacity and point out that higher income is related to possibility of using better health services. On the other hand income is also related to the other components of human capital. Baldacci et al. (2008) relate higher income to the demand for education. Novignon et al. (2012) associate per capita income to the demand for health services.

Gini coefficient. According to literature analysis a greater income inequality (expresses in Gini coefficient) is related to poorer health status (Filmer \& Pritchett, 1999). This control variable is also used by Kim, Lane (2013), Rajkumar \& Swaroop (2008).
Education level. The literature analysis also shows an existence of close relationship between education and health. Baldacci et al. (2008) relate education level to public awareness and state that a higher education level increases public awareness. They also emphasize that an education level influences individual capabilities related with their health needs.

Urbanization level. Based on the previous studies urbanization is related to better access to education and with a health status of population (Baldacci et al., 2008). Gupta, Verhoeven, \& Tiongson (2002) also point out that parents' propensity to send children to school is related to urbanization. Also, opportunity of lower private education costs is identified.

Rate of ageing population. Variables related to population age structure are included in several studies (Kim \& Lane, 2013; Novignon et al., 2012). It is expected that the increase part of population that are older than 65 years is related with a negative impact to health state. This impact is explained by the possibility to increasing death rates (Novignon et al., 2012).

Alcohol consumption. Grossman (2000) defines alcohol consumption as one of health inputs. Alcohol consumption is related to behavioural factors affecting a state of health. Researchers such as Nixon \& Ulmann (2006) mentioned this variable in their study where the relationships between health care expenditure and health outcomes are analysed. It is expected that there is an inverse relationship between alcohol consumption and health status (human capital).

\section{Evaluation Method}

To evaluate the impact of public health expenditure, panel data was used and ordinary least square (OLS), fixed effects (FE) and random effects (RE) models have been developed. According to Rahman \& Khanam (2018) panel data evaluation is superior compared to time series or cross sectional analysis. The basic evaluation model could be expressed as follows:

$$
\begin{aligned}
& \ln H C_{i t}=\alpha+\beta_{I} \ln G O V H_{i t}+ \\
& \beta_{2} \ln G D P P_{-} C_{-} P P S_{i t}+\beta_{3} \ln G I N I_{i t}+ \\
& \beta_{4} \ln P O P \_ \text {PRIMARY } Y_{i t}+\beta_{5} \ln A L C O H O L \_C O N S_{i t} \\
& +\beta_{6} \ln A \bar{G} E_{-} D E P_{i t}+\beta_{7} \ln U R B \_P O P_{i t}+\bar{\varepsilon}_{i t}
\end{aligned}
$$

where: $\alpha-$ constant, $\beta_{\mathrm{n}}$ - coefficient of selected independent variable, $\mathrm{HC}$ - human capital related to health and measured by life expectancy at birth, GOV_HE - general government health expenditure (\% of GDP), GDP_PC_PPS GDP per capita in PPS, GINI - Gini coefficient of equivalised disposable income, POP_PRIMARY - percentage of 15-64 age population with less than primary, primary and lower secondary education (levels 0-2), URB_POP - urban population (\%), AGE_DEP - old age dependency ratio, ALCOHOL_CONS - recorded alcohol per capita consumption, i-country, t- time, $\varepsilon$ - error term.

Variables are transformed to logs and results are evaluated as the coefficients of elasticities. This decision is justified by the practice of previous studies (for example, Filmer \& Pritchett (1999)). In order to form a reliable model data pre-test was performed. The collinearity of the independent variables was evaluated based on Variance Inflation Factor (VIF) while a correlation matrix also was formed in order to avoid multicollinearity. The choice between the formed models was based on 3 tests. The OLS or 
RE model was evaluate based on results of Breusch-Pagan LM test, the Hausman test was used to choose between RE or FE models, whereas the F-test was used to choose between FE and OLS models.

\section{Data}

In order to assess the impact of public health expenditure on human capital unbalanced panel data covering 28 European Union (EU) countries and the period 2000-2017 is used. The number of observations is limited by shortage of a statistical information for a longer time periods. The data of variables such as old age dependency ratio (AGE_DE) and urbanization level (URB_POP) are obtained from the World Bank. World Development Indicators (2019). Another part of variables such as life expectancy (LEF), GDP per capita in
PPS (GDP_PC_PPS), general government health expenditure (GOV_HE), percentage of population (15-64 age) with less than primary, primary and lower secondary education (levels 0-2) (POP_PRIMARY), percentage of population (15-64 age) with tertiary education (levels 5-8) POP_TERT), the Gini coefficient of equivalised disposable income (GINI) are obtained from Eurostat (2018) data base, while recorded alcohol per capita consumption (ALCOHOL_CONS) data is obtained from WHO. Global Health Observatory Data Repository (2019). Descriptive statistics of the analysed dependent and independent variables are presented in Table 1. The E-views statistical software package was used for the testing of the developed model.

Descriptive Statistics of used Variables

\begin{tabular}{|c|c|c|c|c|c|c|}
\hline Variable & Abbreviation & Mean & Min. & Max. & Std, Dev & Observations \\
\hline Life expectancy at birth & LEF & 78,27 & 70,20 & 83,50 & 3,24 & 502 \\
\hline Government health expenditure & GOV HE & 6,00 & 2,50 & 8,90 & 1,40 & 503 \\
\hline Government education expenditure & GOV EDU & 5,21 & 2,80 & 7,20 & 0,98 & 503 \\
\hline GDP per capita & GDP PC PPS & 24351,59 & 5100,00 & 78800,00 & 11300,06 & 504 \\
\hline GINI coefficient & GINI & 29,69 & 22,00 & 40,20 & 3,95 & 431 \\
\hline $15-64$ age population with $0-2$ education level & POP PRIMARY & 30,57 & 12,00 & 79,50 & 13,61 & 498 \\
\hline $15-64$ age population with 5-8 education level & POP TERT & 22,30 & 4,90 & 40,40 & 7,84 & 498 \\
\hline Alcohol consumption per capita & ALCOHOL_CONS & 10,84 & 5,88 & 17,75 & 2,09 & 469 \\
\hline Old age dependency ratio & AGE DEP & 24,59 & 15,16 & 35,14 & 4,30 & 504 \\
\hline Urban population $(\%)$, & URB_POP & 72,05 & 50,75 & 97,96 & 12,42 & 504 \\
\hline
\end{tabular}

\section{Results and Discussion}

The cross section FE model was identified as the most appropriate in this case compering results and parameters of OLS, cross section FE and RE models. This selection was confirmed by the results of the Breusch-Pagan LM test, F-test and Hausman test (see Table 2). The results of the basic model (Model 1) for public health expenditure impact on health component of human capital (expressed in a life expectancy at birth) estimation shows that public health expenditure has positive and significant impact on life expectancy. It was identified that 1 percent growth in public health expenditure increases life expectancy in an average by 0,027 percent. The impact coefficient in the first model is equal to 0,027 in second model to 0,029 and in the third model to 0,026 .

This results conforms with previous studies where a positive impact of public health expenditure was also identified. Positive and significant impact of government health expenditure to life expectancy at birth was identified by Kim \& Lane (2013) in 17 OECD countries study. It was found that 1 percent increase of public health expenditure affects life expectancy by 0,026 . However, it should be noted that in this case public health expenditure are estimated as percent of total health expenditures. While Novignon et al. (2012) for their study used public and private health care expenditure as percentage GDP. The results obtained were expressed in years of life expectancy and it was identified that 1 percentage increase in public and private health expenditure is related to 1 and 0.5 years life expectancy improvement in the fixed effect model and to 1 and 0.4 years improvement in the random effect model. Jaba et al., (2014) analysed total health expenditures per capita and also found the existence of significant relationship between this type of expenditure and life expectancy improvements in 175 countries. The calculated coefficients of the health expenditure per capita was 0.000963 in the European region. Based on Gallet \& Doucouliagos (2017) the healthcare spending elasticity for life expectancy is near 0.04 . Researchers also noticed that the greater impact of health expenditure is in cases were life expectancy is measured at old age. On the other hand Asiskovitch (2010) highlights of existing differences between male and female life expectancy an their health related behaviour. However Asiskovitch (2010) similarly like Nixon, Ulmann (2006) defines healthcare expenditure as a marginal factor in life expectancy.

In summary, the comparability of the results of different studies is complicated by the fact that different researchers use different expressions of health expenditure and carry out different assessment methods. In one case, the results are evaluated as elasticity coefficients, in another case the change in life expectancy in years is evaluated. Table 2

Table 2

Results of Fixed Effects Models Evaluating the Impact of Public Health Expenditure and other Explanatory Variables on Life Expectancy

\begin{tabular}{|c|c|c|c|}
\hline Variable (in logs) & Model 1 & Model 2 & Model 3 \\
\hline Constant & $3.793(0.114)^{* * *}$ & $3.721(0.104)^{* * *}$ & $3.777(0.120)^{* * *}$ \\
\hline Government health expenditure & $0.027(0.004)^{* * *}$ & $0.029(0.004)^{* * *}$ & $0.026(0.005)^{* * *}$ \\
\hline Government education expenditure & & & $0.003(0.006)$ \\
\hline GDP per capita & $0.040(0.004)^{* * *}$ & $0.038(0.004)^{* * *}$ & $0.040(0.004)^{* * *}$ \\
\hline
\end{tabular}


Rasa Railaite, Ruta Ciutiene. The Impact of Public Health Expenditure on Health Component of Human Capital

\begin{tabular}{|c|c|c|c|c|}
\hline & Variable (in logs) & Model 1 & Model 2 & Model 3 \\
\hline \multicolumn{2}{|l|}{ GINI } & $-0.009(0.007)$ & $-0.008(0.007)$ & $-0.009(0.007)$ \\
\hline \multicolumn{2}{|c|}{ 15-64 age population with $0-2$ education level (\%) } & $-0.037(0.005)^{* * *}$ & & $-0.036(0.005)^{* * *}$ \\
\hline \multicolumn{2}{|c|}{ 15-64 age population with 5-8 education level (\%) } & & $0.030(0.003)^{* * *}$ & \\
\hline \multicolumn{2}{|c|}{ Alcohol consumption per capita } & $-0.017(0.005)^{* * *}$ & $-0.017(0.005)^{* * *}$ & $-0.016(0.005)^{* * *}$ \\
\hline \multicolumn{2}{|c|}{ Old age dependency ratio } & $0.044(0.007)^{* * *}$ & $0.040(0.007)^{* * *}$ & $0.044(0.007)^{* * *}$ \\
\hline \multicolumn{2}{|c|}{ Urban population (\%), } & $0.040(0.026)$ & $0.012(0.025)$ & $0.042(0.026)$ \\
\hline \multicolumn{2}{|c|}{$R$-squared } & 0.974 & 0.976 & 0.974 \\
\hline \multicolumn{2}{|c|}{$F$-statistic } & $389.470 * * *$ & $421.485 * * *$ & $377.48 * * *$ \\
\hline \multicolumn{2}{|r|}{ Durbin-Watson stat } & 0.535 & 0.546 & 0.532 \\
\hline \multicolumn{2}{|r|}{ Pesaran CD } & $10.57 * * *$ & $9.43^{* * *}$ & $10.38 * * *$ \\
\hline \multicolumn{2}{|r|}{$\operatorname{VIF}(\max )$} & 3.57 & 1.86 & 1.77 \\
\hline \multirow{3}{*}{$\begin{array}{l}\text { Model } \\
\text { selection } \\
\text { tests }\end{array}$} & F-test, Cross-section Chi-square & $834.27 * * *$ & $923.90 * * *$ & $834.21 * * *$ \\
\hline & Hausman Test, Chi-Sq, Statistic & $50.42 * * *$ & $15.19 * *$ & $48.48 * * *$ \\
\hline & Breusch-Pagan LM test, cross- section & $1294.05 * * *$ & $1638.15 * * *$ & $1296.22 * * *$ \\
\hline & Observations & 393 & 393 & 393 \\
\hline
\end{tabular}

T-statistics are given in brackets, ${ }^{*}-p<0.1 ; *^{*}-p<0.05,{ }^{* * *}-p<0.01$

Asiskovitch (2010) states that two approaches are used to explain health systems impact to health outcomes. It is materialist and neo-materialist approaches. Based on the first approach such aspects as income, education, position in the labour force influence health outcomes such as life expectancy. Considering that education is identified as an important input in health and human capital two models were created: Model 1 with control variable related with lower education level (percentage of population (15-64 age) with less than primary, primary and lower secondary education (levels $0-2)$ ) and Model 2 with control of higher education level (percentage of population (15-64 age) with tertiary education (levels 5-8)). The results showed that in both cases the impact coefficient of public health expenditure remained similar. However, it was confirmed that lower population education level negatively impacts life expectancy while higher education level positively impacts selected health outcome (see Table 2). This effect can be explained on the basis Asiskovitch (2010) who highlights the existing correlation between higher education and health. Such aspects as lifestyle, health-related behaviours, better dietary, not physically difficult or dangerous job positions are stressed. The influence of education also is explained based on Grossman model where education is defined as investment in health.

Human capital could be developed by various types of investments and investment in education is one of the most important. General education expenditure was included in the Model 3 in order to evaluate whether it affects the health component of human capital and also whether this variable involvement make changes in the impact coefficient of health expenditure. The results show that education expenditure has a positive but insignificant impact to the health component. The coefficient of public health expenditure become a little smaller but remains positive and statistically significant.

The theory-based assumptions are also confirmed for almost all other variables. Results of all 3 models shows a positive and significant associations between life expectancy and GDP per capita growth or old age dependency rate growth. However, in the previous studies Kim \& Lane (2013) identify a negative and insignificant impact of changes in the rate of ageing population. Similarly Novignon et al. (2012) estimate a negative and insignificant impact of population under 65 growth on life expectancy at birth. The results also confirmed assumptions related with the impact of GINI and alcohol consumption. It was estimated that increase in GINI coefficient and alcohol consumption are related with a negative impact on life expectancy. However, the impact of GINI coefficient was identified as negative but insignificant, while the impact of alcohol consumption was identified as negative but significant. A positive impact is also identified for population urbanization level, however, the impact is identified as an insignificant.

Based on a high R-squared value it could be concluded that models created explain more than $97 \%$ variation in life expectancy. The good fit of the model is also shown by the Fstatistics which shows that in all 3 models at least one of the coefficient is different from 0 . An evaluation of correlation matrix also shows that a correlation between independent variables are low. The greatest correlation coefficient was identified between GDP per capita and urbanization level $(0,47)$. VIF calculations has shown that the maximum value of the VIF for independent variables is less than 4. This confirms that there are no problems of multicollinearity.

However, the model created have some limitations. Firstly, only cross section FE are included, and this study does not evaluate possible impact of the time effects. In the future studies it could be useful to involve time FE. The Pesaran CD test was performed in order to evaluate the hypothesis that there are no cross-section dependence (correlation) in residuals $\left(\mathrm{H}_{0}\right)$. However, the P-value of Pesaran $\mathrm{CD}$ test is less than 0.05. Taking it into account the results of this study must be evaluated considering this limitations and the model can be improved in the future studies.

\section{Conclusions}

The panel data regression technic usage allowed to estimate the impact of public health expenditure on human capital in 28 EU countries. Annual data from 2000 until 2017 was used to reach a set goal. The life expectancy at birth as a quantitative measure of human capital (with a focus to health component) was selected in this study. The results of cross section FE models allows to make several conclusions. Based on performed literature review it could be concluded that the results differ in the different cases analysed. Some studies confirm the importance of the public sector and its resources for better health and human capital outcomes, while others do not. The results are influenced by case selection, country's income levels, public sector efficiency, geographical location, and other factors. In a case of $28 \mathrm{EU}$ countries it is confirmed that public health expenditure makes a positive and 
significant impact on health as one of the main component of human capital. 3 evaluation models were created with different combination of control variables, but the impact of public health expenditure remained a similar.

The analysis of other control variables also mostly met literature analysis based expectations. Literature relates GDP growth to consumption, nutrition, housing possibilities. A positive impact of such factor was confirmed in this study. The results also showed that the life expectancy also significantly is affected by higher education level. Conversely, the growth of the lower-educated population has a negative impact on life expectancy. Differently like in the previous studies the positive impact of old age dependency growth is identified. The growing part of older population is related with longer life expectancy. Alcohol consumption is defined as a risk behaviour. The results of performed study confirms that increases in alcohol consumption adversely affect the life expectancy. A set of tests and procedures were used to create the appropriate model, but the results of the Pesaran CD test for cross sectional dependency must be taken into account.
Health is an important area of a public policy. The results of performed study shows that higher expenditure in this area affects health outcomes and, in that way, affects human capital in general. However, considering the fact that in most EU countries the rate of public health expenditure is growing it is necessary to use it responsibly. It is necessary to focus to effective health care services and effective resource management. The literature analysis also highlights the importance not only of the effectiveness of health care services, but also of an efficient governance. Considering it, it could be useful to involve more control variables related with government efficiency in the future studies. The results confirm that the impact of public health expenditure is positive, but it is necessary to evaluate its efficiency with a greater focus to new health services created and the results gained. On the other hand, it is necessary to say that this study makes an analyses only with one variable of health status. Considering this limitation, it would be useful to try to find other variables which can express changes in health status and human capital.

\section{References}

Akpolat, A. G. (2014). The Long-Term Impact of Human Capital Investment on GDP : A Panel Cointegrated Regression Analysis. Economics Research International, 220-222. https://doi.org/10.1155/2014/646518

Amadu, I., Eseokwea, N. F., \& Ngambi, M. (2017). Contribution of Public Health Investments to the Economic Growth of Cameroon. Business and Economics Journal, 6(4), 1-9. https://doi.org/10.4172/2151-6219.1000189

Anton, S. G., \& Onofrei, M. (2012). Health care performance and health financing systems in countries from Central and Eastern Europe. Transylvanian Review of Administrative Sciences, (35), 22-32.

Asiskovitch, S. (2010). Gender and health outcomes: The impact of healthcare systems and their financing on life expectancies of women and men. Social Science and Medicine, 70(6), 886-895. https://doi.org/10.1016/ j.socscimed.2009.11.018

Baldacci, E., Clements, B., Gupta, S., \& Cui, Q. (2008). Social Spending, Human Capital, and Growth in Developing Countries. World Development, 36(8), 1317-1341. https://doi.org/10.1016/j.worlddev.2007.08.003

Bloom, D. E., Canning, D., \& Sevilla, J. (2004). The effect of health on economic growth: A production function approach. World Development, 32(1), 1-13. https://doi.org/10.1016/j.worlddev.2003.07.002

Bucinskas, A. (2012). Investicija ị vaikų sveikatą - svarbi žmogiskojo kapitalo kaupimo prielaida darnios pletros kontekste. Tiltai, 3, 213-230.

Cadil, J., Petkovova, L., \& Blatna, D. (2014). Human Capital, Economic Structure and Growth. Procedia Economics and Finance, 12(March), 85-92. https://doi.org/10.1016/S2212-5671(14)00323-2

Dang, A., Likhar, N., \& Alok, U. (2016). Importance of Economic Evaluation in Health Care: An Indian Perspective. Value in Health Regional Issues, 78-83. https://doi.org/10.1016/j.vhri.2015.11.005

Eurostat. (2018). General government expenditure by function. Retrieved from http://appsso.eurostat.ec.europa.eu/ nui/show.do

Farag, M., Nandakumar, A. K., Wallack, S., Hodgkin, D., Gaumer, G., \& Erbil, C. (2013). Health expenditures, health outcomes and the role of good governance. International Journal of Health Care Finance and Economics, 13(1), 3352. https://doi.org/10.1007/s10754-012-9120-3

Ferreira, P. L., Tavares, A. I., Quintal, C., \& Santana, P. (2018). EU health systems classification: A new proposal from EURO-HEALTHY. BMC Health Services Research, 18(1), 1-11. https://doi.org/10.1186/s12913-018-3323-3

Filmer, D., \& Pritchett, L. (1999). The impact of public spending on health: Does money matter? Social Science and Medicine, 49(10), 1309-1323. https://doi.org/10.1016/S0277-9536(99)00150-1

Fleisher, B., Li, H., \& Zhao, M. Q. (2010). Human capital, economic growth, and regional inequality in China. Journal of Development Economics, 92(2), 215-231. https://doi.org/10.1016/j.jdeveco.2009.01.010 
Fujii, T. (2018). Sources of health financing and health outcomes: A panel data analysis. Health Economics, 27(12), 19962015. https://doi.org/10.1002/hec.3817

Gallet, C. A., \& Doucouliagos, H. (2017). The impact of healthcare spending on health outcomes: A meta-regression analysis. Social Science and Medicine, 179, 9-17. https://doi.org/10.1016/j.socscimed.2017.02.024

Giziene, V., Simanaviciene, Z., \& Palekiene, O. (2012). Evaluation of Investment in Human Capital Economical Effectiveness. Inzinerine Ekonomika-Engineering Economics, 23(2), 106-116. https://doi.org/10.5755/j01. ee.23.2.1541

Grossman, M. (2000). The Human Capital Model. Handbook of Health Economics, 1, 347-408. https://doi.org/10. 1016/S1574-0064(00)80166-3

Gupta, S., Verhoeven, M., \& Tiongson, E. R. (2002). The effectiveness of government spending on education and health care in developing and transition economies. European Journal of Political Economy, 18(4), $717-737$. https://doi.org/10.1016/S0176-2680(02)00116-7

Homaie Rad, E., Vahedi, S., Teimourizad, A., Esmaeilzadeh, F., Hadian, M., \& Torabi Pour, A. (2014). Comparison of the Effects of Public and Private Health Expenditures on the Health Status: A Panel Data Analysis in Eastern Mediterranean Countries. International Journal of Health Policy and Management, 1(2), $163-167$. https://doi.org/10.15171/ijhpm.2013.29

Jaba, E., Balan, C. B., \& Robu, I.-B. (2014). The Relationship between Life Expectancy at Birth and Health Expenditures Estimated by a Cross-country and Time-series Analysis. Procedia Economics and Finance, 15(14), $108-114$. https://doi.org/10.1016/S2212-5671(14)00454-7

Kim, T. K., \& Lane, S. R. (2013). Government Health Expenditure and Public Health Outcomes : A Comparative Study among 17 Countries and Implications for US Health Care Reform. American International Journal of Contemporary Research, 3(9), 8-13. Retrieved from http://www.aijcrnet.com/journals/Vol_3_No_9_September_2013/2.pdf

Kokotovic, F. (2016). A Panel Regression Analysis of Human Capital Relevance in Selected Scandinavian and Se European Countries. UTMS Journal of Economics, 7(1), 13-24. Retrieved from http://www.utmsjoe.mk/files/Vol. 7 No. 1/UTMSJOE-2016-0701-02-Kokotovic.pdf

Lee, J., Ihm, J., \& Ryu, D. (2017). Human capital measures and stock return predictability: Macroeconomic versus microeconomic approaches. Finance Research Letters, 21, 53-56. https://doi.org/10.1016/j.frl.2016.12.019

Lim, S. S., Updike, R. L., Kaldjian, A. S., Barber, R. M., Cowling, K., York, H., ... Murray, C. J. L. (2018). Measuring human capital: a systematic analysis of 195 countries and territories, 1990-2016. The Lancet, 392(10154), 1217-1234. https://doi.org/10.1016/S0140-6736(18)31941-X

Marginean, I. (2014). Public Expenditure with Education and Healthcare in EU Countries. Procedia Economics and Finance, 8(14), 429-435. https://doi.org/10.1016/S2212-5671(14)00110-5

Nixon, J., \& Ulmann, P. (2006). The relationship between health care expenditure and health outcomes: Evidence and caveats for a causal link. European Journal of Health Economics, 7(1), 7-18. https://doi.org/10.1007/s10198-0050336-8

Novignon, J., Olakojo, S. A., \& Nonvignon, J. (2012). The effects of public and private health care expenditure on health status in sub-Saharan Africa: new evidence from panel data analysis. Health Economics Review, $2(1), 22$. https://doi.org/10.1186/2191-1991-2-22

Odoardi, I., \& Muratore, F. (2019). The role of human capital after the crisis in Italy: A regional analysis. Socio-Economic Planning Sciences, 66(June 2018), 58-67. https://doi.org/10.1016/j.seps.2018.07.002

Oluwatobi, S. O., \& Ogunrinola, O. I. (2011). Government Expenditure on Human Capital Development: Implications for Economic Growth in Nigeria. Journal of Sustainable Development, 4(3), 72-80. https://doi.org/10.5539/jsd.v4n3p72

Poteliene, S., \& Tamasauskiene, Z. (2014). Zmogiskojo kapitalo konceptualizacija: raida, samprata ir formavimas. Business Systems \& Economics, 4(1), 89-106. https://doi.org/10.13165/VSE-14-4-1-08

Praise, U. I., \& George-Anokwuru, C. C. (2018). Empirical Analysis of Determinants of Human Capital Formation : Evidence from the Nigerian Data. Journal of World Economic Research, 7(2), 73-81. https://doi.org/10. 11648/j.jwer.20180702.14

Prasetyo, A. D., \& Zuhdi, U. (2013). The Government Expenditure Efficiency towards the Human Development. Procedia Economics and Finance, 5(2012), 615-622. https://doi.org/10.1016/S2212-5671(13)00072-5

Rahman, M. M., \& Khanam, R. (2018). Health care expenditure and health outcome nexus : New evidence from the SAARC-ASEAN region. Globalization and Health, 14(113), 1-30. https://doi.org/10.1186/s12992-018-0430-1 
Rajkumar, A. S., \& Swaroop, V. (2008). Public spending and outcomes: Does governance matter? Journal of Development Economics, 86(1), 96-111. https://doi.org/10.1016/j.jdeveco.2007.08.003

Sapuan, N. M., \& Sanusi, N. A. (2013). Cointegration Analysis of Social Services Expenditure and Human Capital Development in Malaysia : a Bound Testing Approach. Journal of Economic Cooperation and Development, 34(1), 2013.

Schultz, T. W. (1972). Human Capital: Policy Issues and Research Opportunities. Economic Research: Retrospect and Prospect, 6, 1-84.

Shuaibu, M., \& Timothy, P. O. (2016). Human Capital Development Dynamics in Africa: Evidence from Panel Cointegration and Causality in 33 Countries. Applied Econometrics and International Development, 16, $2000-2013$. Retrieved from http://www.usc.es/economet/journals1/aeid/aeid16110.pdf

Suhrcke, M., McKee, M., Stuckler, D., Sauto Arce, R., Tsolova, S., \& Mortensen, J. (2005). The contribution of health to the economy in the European Union. Luxembourg: Office for Official Publications of the European Communities. https://doi.org/10.1016/j.puhe.2006.08.011

Tchanturia, N., Beridze, T., \& Kurashvili, G. (2015). Features of Development of the Human Capital in Georgia. Procedia - Social and Behavioral Sciences, 213, 580-585. https://doi.org/10.1016/j.sbspro.2015.11.453

WHO. Global Health Observatory Data Repository. (2018). Recorded alcohol per capita consumption, 2000-2009 by country. Retrieved from https://apps.who.int/gho/data/view.main.52160

Wolff, E. N. (2000). Human capital investment and economic growth: Exploring the cross-country evidence. Structural Change and Economic Dynamics, 11(4), 433-472. https://doi.org/10.1016/S0954-349X(00)00030-8

World Bank. World Development Indicators. (2019). World Development Indicators. Retrieved from https://databank.worldbank.org/source/world-development-indicators/Type/TABLE/preview/on

Zakharova, O., \& Kratt, O. (2014). Economic Study and Risk Estime of the Investment in the Human Capital. Economics \& Sociology, 7(2), 94-108. https://doi.org/10.14254/2071-789X.2014/7-2/8

Zhang, C., \& Zhuang, L. (2011). The composition of human capital and economic growth: Evidence from China using dynamic panel data analysis. China Economic Review, 22(1), 165-171. https://doi.org/10.1016/j.chieco.2010.11.001

The article has been reviewed.

Received in January 2020; accepted in June 2020. 